\title{
Interest in Health Information Exchange in Ambulatory Care: A Statewide Survey
}

\author{
E. Tham'; S. E. Ross²; B. K. Mellis'; B. L. Beaty ${ }^{3}$; L. M. Schilling ${ }^{2}$; A. J. Davidson ${ }^{4}$
}

'University of Colorado Denver Department of Pediatrics; ${ }^{2}$ University of Colorado Denver Division of General Internal Medicine; ${ }^{3}$ Colorado Health Outcomes Program; ${ }^{4}$ Public Health Informatics, Denver Public Health, Denver, Colorado

\section{Keywords}

Ambulatory care information systems, communication, questionnaires

\section{Summary}

Objective: Assess the interest in and preferences of ambulatory practitioners in HIE.

Background: Health information exchange (HIE) may improve the quality and efficiency of care. Identifying the value proposition for smaller ambulatory practices may help those practices engage in HIE.

Methods: Survey of primary care and specialist practitioners in the State of Colorado.

Results: Clinical data were commonly (always [2\%], often [29\%] or sometimes [49\%]) missing during clinic visits. Of 12 data types proposed as available through HIE, ten were considered "extremely useful" by most practitioners. "Clinical notes/consultation reports," "diagnosis or problem lists," and "hospital discharge summaries" were considered the three most useful data types. Interest in EKG reports, diagnosis/problem lists, childhood immunizations, and discharge summaries differed among ambulatory practitioner groups (primary care, obstetrics-gynecology, and internal medicine subspecialties).

Conclusion: Practitioners express strong interest in most of the data types, but opinions differed by specialties on what types were most important. All providers felt that a system that provided all data types would be useful. These results support the potential benefit of HIE in ambulatory practices.

\section{Correspondence to:}

Eric Tham MD

University of Colorado Denver

Department of Pediatrics

Section of Emergency Medicine

13123 E 16th Ave, B251

Aurora, CO 80045, USA

E-mail: Tham.Eric@tchden.org
Appl Clin Inf 2010; 1: 1-10

doi: 10.4338/ACI-2009-10-RA-0007

received: November 2, 2009

accepted after major revision: January 18, 2010

published: February 3, 2010 


\section{Introduction}

With a soaring US healthcare system budget [1], quality and efficiency seem suboptimal; US health outcomes unfavorably compare with many countries [2]. Health information exchange (HIE) has been touted as a key element for improving healthcare system quality and efficiency and a "strong information infrastructure" [3]. An economic model suggests that fully implemented and interoperable HIE would net $\$ 77.8$ billion annually in the US [4].

With estimated financial benefit, HIE placed prominently in recent US federal government activities [5]. Ambulatory practice HIE participation remains challenged [6] by limited provider electronic health records (EHR) adoption [7], limited interoperability capacity, and lack of technical and financial resources. With ambulatory practice adoption incentives and state-specific HIE funding efforts [5], engaging ambulatory practitioners means including the full spectrum of practice configurations from solo practices to large group practices. Most US practitioners provide care in small and medium practice sites [8], where data are generated and consumed. Factoring these practice perspectives in HIE development will significantly impact assessed and perceived quality, efficiency, return on investment, and viability of HIEs.

Exchanging a narrow set of data types increased the likelihood of Regional Health Information Organization's (RHIOs) continued operations and involving ambulatory physicians was associated with a higher likelihood of financial viability [9]. Identifying the key data types most valuable to ambulatory providers will aid HIE developers to design future HIEs that will remain operational and viable [9]. One previous study assessed the data types physicians valued for HIE, but it was targeted at emergency department physicians [10]. The purpose of our study was to assess the value of HIE data types for ambulatory providers.

\section{Objectives}

To promote widespread EHR adoption effectively, the value proposition analysis for key stakeholders, [11-16] must be established, and the successful HIE will be committed to provide that value. Value among emergency physicians for HIE was defined as access to ECGs and discharge summaries [10]. Although clinically useful data is frequently missing in primary care encounters [17], perceived HIE value in the ambulatory setting, where most care is delivered, is less well defined. We therefore conducted a survey among ambulatory practitioners throughout the State of Colorado to assess the current use of health information technology in the outpatient setting and the perceived value of a future health information exchange system.

\section{Methods}

In 2004, Colorado was awarded an Agency for Healthcare Research and Quality State and Regional Demonstration Project contract [18]. With this and other funding, the Colorado Regional Health Information Organization (CORHIO) was formed to develop a statewide HIE. A survey was developed to assess ambulatory practitioner perspectives, interests and preferences for HIE. Survey questions assessed how often ambulatory physicians were missing information and which HIE data types would be most useful. A list of 12 HIE data types was developed after initial interviews with a group of key stakeholders and experts associated with the RHIO. Questions were pilot tested by general internists at a teaching hospital to confirm face validity and clarity.

Survey methods were approved by the Colorado Multiple Institutional Review Board. The study was anonymous and tracking numbers were used to confirm return of surveys. The survey population consisted of Colorado ambulatory physicians in primary care (general internal medicine, pediatrics, family practice, and general practice), obstetrician gynecologists, and internal medicine specialties (pulmonary medicine, cardiology, gastroenterology, nephrology, infectious diseases, and rheumatology). The sample frame consisted of physicians listed in the Colorado Coalition on Family Medicine dataset as ambulatory physicians; the dataset further classified ambulatory physicians into the three categories: primary care, obstetrician gynecologists, and internal medicine specialties. From the original sample frame of 1588 primary care physicians and 1486 specialist physicians, we 
obtained a probability sample of 621 primary care physicians and 611 specialist physicians. Questionnaires were mailed in September 2007. Potential respondents were initially mailed a postcard introducing the survey. One week later, a written questionnaire was mailed with a business reply envelope, followed by a reminder card two weeks later. Four weeks after the first questionnaire mailing, a second questionnaire was mailed to non-responders, followed by a final reminder card two weeks after that.

\section{Analysis}

Simple frequencies were calculated for individual survey responses for the group as a total number and for the three physician types. Student's t-tests were used to determine if there were differences between the three specialty groups.

\section{Results}

A total of 1232 surveys were sent to physicians who saw patients in outpatient settings. Fifty (4\%) of the surveys were returned due to incorrect addresses. Responses received were 618 (response rate of $52 \%)$. Of these, $35(6 \%)$ reported that they were not currently seeing patients in an outpatient setting. Removing these left 583 responses in the analysis cohort. The characteristics of the physicians in our survey are shown in Table 1. Most were urban and were either group, single specialty, or single or two-person practices. Most physicians claimed access to electronic interfaces which allowed review of some outside outpatient clinical notes, laboratory results, radiology reports, and inpatient data. Nonetheless, $31 \%$ of practitioners reported missing needed data in outpatient practice "always" or "often," $49 \%$ reported missing data "sometimes," and 18\% reported missing data "seldom" (2\% responded "never").

Respondents were asked to "Consider a new computer system in your office that provided patient information from hospitalizations, emergency departments visits, previous physicians, and outside consultations." They were then asked to rate a list of 12 data types as extremely useful, moderately useful, and slightly useful. All but three of the items were rated as "extremely useful" by more than two thirds of physicians ( Fig. 1). EKG results, childhood immunizations, and family history were less commonly rated as extremely useful. Ratings only differed among the three groups of respondents (primary care physicians, obstetrician gynecologists, and internal medicine specialists) for four data types: childhood immunizations, electrocardiograms, diagnosis/problem lists, and discharge summaries ( Table 2).

Respondents were also asked, "Which one of the above would be the most useful addition to your current practice?" The top six responses overall were clinical notes/consultation reports, diagnosis/problem lists, hospital discharge summaries, lab test results, medications filled by patient, and medications prescribed by practitioners ( Fig. 2). Variation in rankings among the three respondent groups are shown in $\mathbf{T a b l e} 3$. The top 6 desired types were similar among the groups, although primary care physicians ranked childhood immunizations higher than prescribed medications, and obstetrician gynecologists ranked pathology and radiology reports above all medication information. Some of those who gave no response indicated that they already had access to these data types.

Respondents were asked "Overall, how useful would it be for your outpatient practice to have a new computer system that provided patient information from hospitalizations, emergency department visits, previous physicians, and outside consultation?" "Extremely useful" was chosen by $70 \%$ $(\mathrm{n}=405)$ of all respondents, $20 \%(\mathrm{n}=116)$ chose moderately useful, and $8 \%(\mathrm{n}=48)$ chose slightly useful. "Already have all" was chosen by $1.2 \%(\mathrm{n}=7)$.

\section{Discussion}

More than $60 \%$ of the outpatient physicians who participated in our survey had access to some outside electronic data including clinic notes, laboratory results, radiology reports, and inpatient 
data. This adoption rate was similar to previous surveys on electronic health record use [19]. Even so, the respondents reported often (29\%) or sometimes (49\%) needing missing clinical information at the time of the visit. A previous survey of missing clinical information during primary care visits found that missing clinical data is a common problem. In that study, most of the missing information originated outside of the provider's clinical system, obtaining missing information was likely to consume time and resources, and the missing clinical information was perceived as somewhat likely to adversely affect care [17]. HIE in the ambulatory setting would facilitate locating and retrieving all categories of clinical information that were missing in their systems, including the most common types of laboratory results, letters/dictations, and radiology results. The data types most valued by ambulatory physicians in our study can be used by HIE developers to guide system design and facilitate development of processes for discovery of missing clinical information.

A significant majority of surveyed physicians anticipated great utility for nearly all proposed data types made available through HIE, and responses were generally similar across specialties. Concordance about the value of sharing a common core target data set may improve decision making and reduce medical errors as patients commonly transition among ambulatory practices. Ambulatory providers most highly prioritized clinical notes and consultation reports, diagnosis or problem lists, hospital discharge summaries, and laboratory test results. Notably, high value was placed not only on coded data that is part of the ASTM Continuity of Care Record standard (e.g. diagnosis or problem list and laboratory test results), but also on narrative/free text reports, e.g. notes, reports and discharge summaries, that fall outside of this standard [20].

Our study results help to identify HIE data priorities for ambulatory practice stakeholders. Although there were considerable similarities among preferred data types among specialties, the differences are also notable and highlight the difficulties in designing a "one size fits all" system for physicians. For example in the study of emergency physicians, the authors found that EKG results were the single most important data type while in our study, outpatient providers rated EKG results as a lower priority [10].

As described in the lessons learned from the Santa Barbara County Care Data Exchange experience, an incremental approach with an initial implementation of a few highly valued data types may be more successful than an implementation plan which includes all available data types. [21]. This approach is also suggested by a study that found RHIOs that exchanged fewer data types were more likely to be operational [9]. Our results suggest that a "one size fits all" approach may not be successful and that specialty specific customization in the data types provided and how they are viewed may be necessary.

Finally, a majority of physicians in our survey indicated that a system that provided all the data types would be extremely useful (64\%) or moderately useful (27\%) with no significant difference between the specialties. This suggests that most ambulatory physicians would find it useful to adopt electronic HIE systems to locate needed clinical information that is missing from the patients' paper or electronic chart. It is notable that this interest in adopting HIE in the ambulatory setting conceivably could provide a bridge to EHR adoption. In a survey of ambulatory physicians, a major barriers to EHR adoption included capital costs, not finding a system that met their needs, uncertainty about their return on the investment, and concern that a system would become obsolete [7]. An HIE system that is well accepted by ambulatory physicians without EHR could overcome these barriers by providing a platform for additional modules that provide EHR functions (e.g. review of test results, electronic prescribing, and medication reconciliation). Such architecture could provide EHR capabilities at reasonable cost without the large capital outlays that on-site systems require, and could be updated to reflect evolving standards of meaningful use without requiring practices to invest in new computers and software applications.

\section{Limitations}

The survey limited its scope to outpatient physicians, thus may not be generalizable to other specialties or practice domains such as inpatient physicians or surgeons. However, missing information has been shown to be a significant factor in outpatient care [17]. While the survey was limited to physicians in the State of Colorado there is little reason to believe major differences with other regions in the United States. Our survey sample was based on physician and not by practice, thus 
we may have oversampled large practices. Lastly, the large percentage of urban physicians with prior access to electronic records may have biased the results given greater prior experience with electronic access.

\section{Conclusions}

While progress has been made in the adoption of electronic health records in the outpatient setting and many physicians have electronic access to some of the outside data types needed for the care of their patients, there still is a gap in available information. Health information exchanges as suggested by recent federal legislation and investments [5] would provide most of that information. Most physicians surveyed stated that most of the data types would be extremely useful, but when asked to prioritize them, the physician types differed significantly on what was most important to them. However, all respondents felt that a system that provided all of this information would be useful. While this suggests a general enthusiasm for HIE, it still remains that developers of HIE systems must design functionality that is appealing to multiple physician specialties and subspecialties as the federal government set standards for meaningful use [22] and offers incentives for adoption of this technology.

\section{Clinical Relevance Statement}

This study will help aid designers and implementers of future health information exchange systems prioritize the data types to implement in future systems for ambulatory practitioners. The implication of this study for ambulatory practitioners is that it will help practitioners prioritize the data types that they request from vendors and developers of health information exchanges.

\section{Acknowledgments}

We appreciate the assistance of Ms. Linda Niebauer and the Colorado Coalition on Family Medicine for providing the dataset of Colorado physicians. 


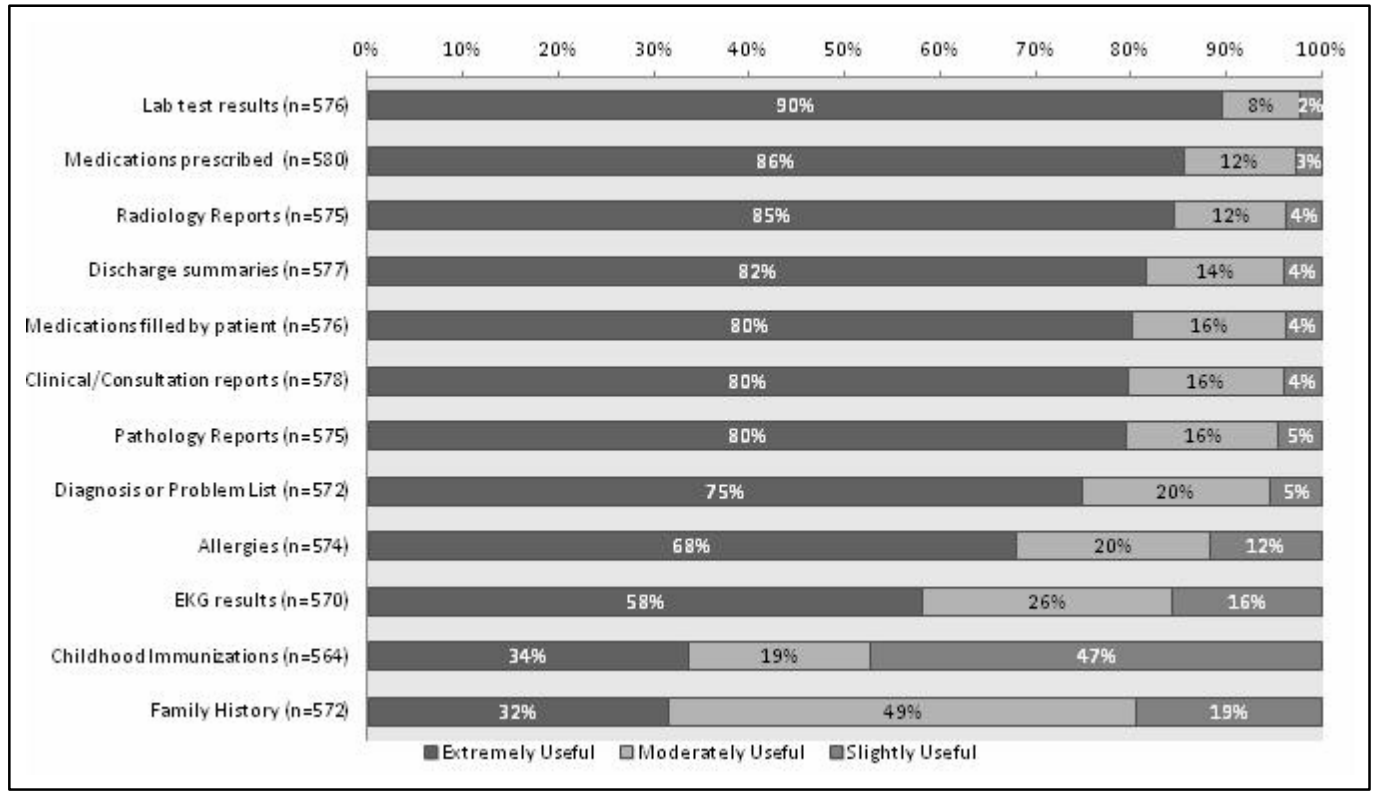

Fig. 1 Utility of specific data types

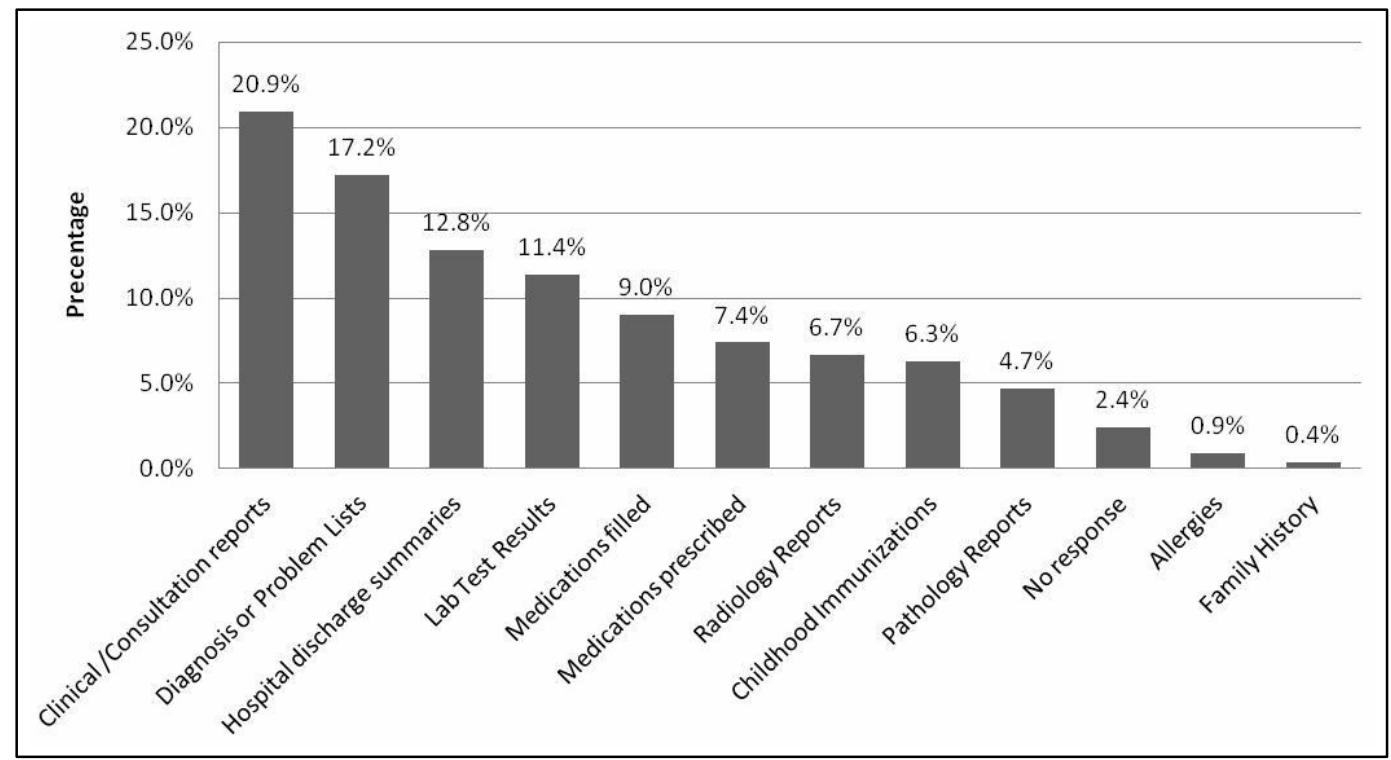

Fig. 2 Most useful additions to current practice 
Table 1 Practice characteristics

\begin{tabular}{|l|l|l|}
\hline Specialty & $\mathbf{n}$ & $\%$ \\
\hline Primary care & 276 & 47 \\
\hline Obstetrics-gynecology & 101 & 17 \\
\hline Internal medicine specialist & 206 & 35 \\
\hline Practice type & $\mathbf{n}$ & $\%$ \\
\hline Solo or two-person practice & 114 & 20 \\
\hline Group practice: single specialty & 242 & 41 \\
\hline Group practice: multi-specialty & 59 & 10 \\
\hline Hospital-owned practice & 85 & 15 \\
\hline Staff-model HMO & 78 & 14 \\
\hline Location & $\mathbf{n}$ & $\%$ \\
\hline Urban & 561 & 96 \\
\hline Rural & 22 & 4 \\
\hline Practice technology & $\mathbf{n}$ & $\%$ \\
\hline Review outpatient clinical notes on a computer screen & 361 & 62 \\
\hline Review outpatient laboratory results on a computer screen & 422 & 73 \\
\hline Review outpatient radiology reports on a computer screen & 435 & 75 \\
\hline Write prescriptions using a computer & 232 & 40 \\
\hline Accept email sent by patients & 266 & 46 \\
\hline Electronic access to inpatient data & 446 & 77 \\
\hline
\end{tabular}


Table 2 Differing ratings for data types by specialty

\begin{tabular}{|c|c|c|c|c|c|c|c|}
\hline \multirow[t]{3}{*}{ Data type } & \multicolumn{7}{|c|}{$\begin{array}{l}\text { Number and proportion ranking data type as "extremely } \\
\text { useful" }\end{array}$} \\
\hline & \multicolumn{2}{|c|}{$\begin{array}{l}\text { Primary care } \\
(n=276)\end{array}$} & \multicolumn{2}{|c|}{$\begin{array}{l}\text { Obstetrics- } \\
\text { gynecology } \\
(n=101)\end{array}$} & \multicolumn{2}{|c|}{$\begin{array}{l}\text { Internal medi- } \\
\text { cine specialists } \\
(n=206)\end{array}$} & \multirow[t]{2}{*}{$\begin{array}{l}p- \\
\text { value }\end{array}$} \\
\hline & n & $\%$ & n & $\%$ & n & $\%$ & \\
\hline EKG results & 201 & 74 & 36 & 37 & 94 & 47 & $<0.001$ \\
\hline Diagnosis/problem list & 223 & 82 & 65 & 65 & 140 & 70 & 0.001 \\
\hline Childhood immunizations & 161 & 59 & 11 & 11 & 18 & 9 & 0.001 \\
\hline Discharge summaries & 232 & 85 & 72 & 71.3 & 167 & 82.3 & 0.03 \\
\hline Radiology reports & 230 & 85 & 92 & 92 & 165 & 81 & 0.11 \\
\hline Medications prescribed by practitioners & 235 & 86 & 80 & 79 & 182 & 88 & 0.14 \\
\hline Allergies & 195 & 73 & 66 & 66 & 129 & 62.9 & 0.16 \\
\hline Pathology reports & 217 & 80 & 87 & 87 & 153 & 75 & 0.19 \\
\hline Family history & 95 & 35 & 30 & 30 & 55 & 27 & 0.32 \\
\hline Clinical notes/consultation reports & 220 & 81 & 75 & 74 & 165 & 81 & 0.61 \\
\hline Medications filled by patients & 218 & 80 & 78 & 77 & 165 & 81 & 0.74 \\
\hline Lab test results & 244 & 89 & 91 & 90 & 181 & 89 & 0.78 \\
\hline
\end{tabular}


Table 3 Most useful addition to current practice by specialty

\begin{tabular}{|c|c|c|c|c|c|c|c|c|}
\hline \multirow[t]{2}{*}{$\begin{array}{l}\text { Most useful } \\
\text { addition }\end{array}$} & \multicolumn{2}{|c|}{ Total } & \multicolumn{2}{|c|}{ Primary care } & \multicolumn{2}{|c|}{$\begin{array}{l}\text { Obstetrics- } \\
\text { gynecology }\end{array}$} & \multicolumn{2}{|c|}{$\begin{array}{l}\text { Internal medi- } \\
\text { cine specialties }\end{array}$} \\
\hline & $\mathbf{n}$ & $\%$ & $\mathrm{n}$ & $\%$ & $\mathrm{n}$ & $\%$ & $\mathrm{n}$ & $\%$ \\
\hline $\begin{array}{l}\text { Clinical notes/ } \\
\text { consultation reports }\end{array}$ & 116 & 21 & 36 & 14 & 22 & 23 & 58 & 29 \\
\hline Diagnosis or problem lists & 95 & 17 & 54 & 21 & 10 & 10 & 31 & 16 \\
\hline Hospital discharge summaries & 71 & 13 & 41 & 16 & 12 & 12 & 18 & 9 \\
\hline Lab test results & 63 & 11 & 21 & 8 & 13 & 13 & 29 & 15 \\
\hline Medications filled by patient & 50 & 9 & 27 & 11 & 4 & 4 & 19 & 10 \\
\hline $\begin{array}{l}\text { Medications prescribed by } \\
\text { practitioners }\end{array}$ & 41 & 7) & 18 & 7 & 5 & 5 & 18 & 9 \\
\hline Radiology reports & 37 & 7 & 7 & 3 & 20 & 20 & 10 & 5 \\
\hline Childhood immunizations & 35 & 6 & 35 & 14 & 0 & 0 & 0 & 0 \\
\hline Pathology reports & 26 & 5 & 7 & 3 & 8 & 8 & 11 & 6 \\
\hline No response & 13 & 2 & 10 & 4 & 1 & 1 & 2 & 1 \\
\hline Allergies & 5 & 1 & 1 & 0.4 & 2 & 2 & 2 & 1 \\
\hline
\end{tabular}




\section{References}

1. Aaron HJ. Budget crisis, entitlement crisis, health care financing problem which is it? Health Aff 2007; 26: 1622-1633.

2. World Health Organization, Lerberghe Wv. Primary health care: now more than ever. Geneva, Switzerland: World Health Organization 2008.

3. Institute of Medicine (U.S.). Committee on Quality of Health Care in America. Crossing the quality chasm: a new health system for the 21st century. Washington, D.C.: National Academy Press 2001.

4. Walker J, et al. The value of health care information exchange and interoperability. Health Aff 2005 January 19, 2005:hlthaff.w5.10.

5. The American Recovery and Reinvestment Act of 20092009 [cited 2010 January 25]; Available from: http://www.recovery.gov/About/Pages/The_Act.aspx

6. eHealth Initiative Fifth Annual Survey of Health Information Exchange At the State and Local Levels. 2009 [cited 2010 January 25]; Available from: http://www.ehealthinitiative.org/sites/default/files/eHI-HIESurveyResultsFinalReport-2008.pdf

7. DesRoches CM, et al. Electronic health records in ambulatory care - a national survey of physicians. N Engl J Med 2008; 359: 50-60.

8. Nyweide DJ, et al. Relationship of primary care physicians' patient caseload with measurement of quality and cost performance. JAMA. 2009; 302: 2444-2450.

9. Adler-Milstein J, Landefeld J, Jha AK. Characteristics associated with regional health information organization viability. J Am Med Inform Assoc.. 2010; 17: 61-65.

10. Shapiro JS, et alThe New York clinical information exchange clinical advisory S. emergency physicians' perceptions of health information exchange. J Am Med Inform Assoc. 2007; 14: 700-705.

11. Miller RH, Miller BS. The Santa Barbara county care data exchange: What happened? Health Aff 2007; 26: w568-w580.

12. Brailer DJ. From Santa Barbara to Washington: A person's and a nation's journey toward portable health information. Health Aff. 2007; 26: w581-w588.

13. Grossman JM, Bodenheimer TS, McKenzie K. Hospital-physician portals: The role of competition in driving clinical data exchange. Health Aff. 2006; 25: 1629-1636.

14. Adler-Milstein J,et al. The state of regional health information organizations: current activities and financing. Health Aff. 2008; 27: w60-w69.

15. Grossman JM, Kushner KL, November EA. Creating sustainable local health information exchanges: can barriers to stakeholder participation be overcome? Res Briefs. 2008;2: 1-12.

16. Marchibroda JM. Health information exchange policy and evaluation. Journal of Biomedical Informatics. 2007; 40((Suppl. 1): S11-S6.

17. Smith PC et al. Missing clinical information during primary care visits. JAMA. 2005; 293: 565-571.

18. AHRQ. Health information technology: state and regional demonstration projects. February 2007 [cited 2009 April 30]; Available from: http://www.ahrq.gov/research/hitdemoproj.htm

19. Simon SR, et al. Physicians and electronic health records: A statewide survey. Arch Intern Med2007; 167: 507-512.

20. ASTM. ASTM E2369 - 05e1 Standard specification for continuity of care record (CCR). West Conshohocken, PA: ASTM International 2005.

21. Frohlich J, et alRetrospective: lessons learned from the Santa Barbara project and their implications for health information exchange. Health Aff. 2007; 26: w589-w591.

22. Office of the National Coordinator. Meaningful Use. 2009 [cited 2010 January 10]; Available from: http://healthit.hhs.gov/portal/server.pt?open=512\&objID=1325\&parentname=CommunityPage\&parenti $\mathrm{d}=1$ \&mode $=2$ 